\title{
Human Fibroblasts as a Model for the Study of Bone Disorders
}

\author{
Lauria Claeys ${ }^{1}$, Nathalie Bravenboer ${ }^{2}$, Elisabeth M. W. Eekhoff ${ }^{3}$ and Dimitra Micha ${ }^{1 *}$ \\ ${ }^{1}$ Department of Clinical Genetics, Amsterdam Movement Sciences, Amsterdam UMC, Vrije Universiteit Amsterdam, \\ Amsterdam, Netherlands, ${ }^{2}$ Department of Clinical Chemistry, Amsterdam Movement Sciences, Amsterdam UMC, Vrije \\ Universiteit Amsterdam, Amsterdam, Netherlands, ${ }^{3}$ Department of Internal Medicine Section Endocrinology, Amsterdam \\ Movement Sciences, Amsterdam UMC, Vrije Universiteit Amsterdam, Amsterdam, Netherlands
}

\section{OPEN ACCESS}

Edited by:

Claire Elizabeth Clarkin

University of Southampton,

United Kingdom

Reviewed by:

David M. Findlay,

University of Adelaide, Australia

Sudip Sen,

All India Institute of Medical

Sciences, India

*Correspondence:

Dimitra Micha

d.micha@amsterdamumc.nı

Specialty section:

This article was submitted to

Bone Research,

a section of the journal

Frontiers in Endocrinology

Received: 30 August 2019

Accepted: 18 May 2020

Published: 19 June 2020

Citation:

Claeys L, Bravenboer N, Eekhoff EMW and Micha D (2020) Human

Fibroblasts as a Model for the Study of Bone Disorders.

Front. Endocrinol. 11:394. doi: 10.3389/fendo.2020.00394
Bone tissue degeneration is an urgent clinical issue, making it a subject of intensive research. Chronic skeletal disease forms can be prevalent, such as the age-related osteoporosis, or rare, in the form of monogenetic bone disorders. A barrier in the understanding of the underlying pathological process is the lack of accessibility to relevant material. For this reason, cells of non-bone tissue are emerging as a suitable alternative for models of bone biology. Fibroblasts are highly suitable for this application; they populate accessible anatomical locations, such as the skin tissue. Reports suggesting their utility in preclinical models for the study of skeletal diseases are increasingly becoming available. The majority of these are based on the generation of an intermediate stem cell type, the induced pluripotent stem cells, which are subsequently directed to the osteogenic cell lineage. This intermediate stage is circumvented in transdifferentiation, the process regulating the direct conversion of fibroblasts to osteogenic cells, which is currently not well-explored. With this mini review, we aimed to give an overview of existing osteogenic transdifferentiation models and to inform about their applications in bone biology models.

Keywords: fibroblast, preclinical model, osteoblast, bone disease, osteogenic transdifferentiation

\section{INTRODUCTION}

Bone disorders encompass a wide range of chronic disorders with diverse etiologies, including both genetic and environmental factors. Next generation sequencing has contributed to the identification of the responsible genomic loci for several of the 500 Mendelian bone disorders, which has expanded our understanding of bone biology and its pathology in more frequent conditions, such as fractures at a postmenopausal age $(1,2)$. Nonetheless, for many of these patients this information remains to be translated into meaningful therapies. This gap between the genetic breakthrough and treatment can be largely attributed to the lack of cell models relevant for the study of bone tissue, in which the (genetic) defect can be examined and interrogated for the exploration of a therapeutic intervention. Such a model also offers the prospect of screening the large number of genetic variants of questionable pathogenicity, which are frequently found in exome analyses (3).

The paucity of bone material, which can be understandably explained by the invasive nature of the biopsy, has prompted efforts for the invention of bone cell models, which can faithfully recapitulate the disease mechanism by making use of more accessible patient materials. In the recent years, the attention toward fibroblasts as a starting point for differentiation to other cell types, including osteoblasts, has been growing. Fibroblasts are a common resident cell type in connective tissue found almost ubiquitously in the human body, including the easily accessible skin. Despite 
their recognition as a prominent cell type for about a century (4), their characterization remains obscure due to the lack of suitable markers and their uncharacterized diversity (5). However, their potential in osteogenesis can be demonstrated both in nature, in disorders of pathological ossification, as well as in more artificial systems of in vitro osteogenic differentiation. This allows the consideration of fibroblast-based models for the study of bone disorders. Particularly, this review focuses on human fibroblastbased models of osteogenic transdifferentiation for modeling of osteoblast-dependent disorders (Table 1).

\section{BONE BIOLOGY}

In order to appreciate the value and shortcomings of relevant cell models, an overview of bone biology is required. The bone tissue typically consists of the mineral and organic components, which confer its stiffness and flexibility, respectively, to ensure its competence during continuous exposure to mechanical stress. Particularly, collagen type I constitutes the largest part of the organic mass; in addition to supporting cell growth and function, it also serves as a scaffold for mineral deposition. Bone tissue adapts to environmental cues by constant remodeling, which is primarily orchestrated by three different cell types, the osteoblasts, osteoclasts, and osteocytes. Osteoblasts have an anabolic role in building bone tissue by secreting the collagenrich extracellular matrix (ECM) whereas osteoclasts perform a catabolic function by degrading the bone tissue. In this setting some of the osteoblasts become buried in the mineralized ECM, which triggers their differentiation to osteocytes. The latter are mechanosensing cells, which coordinate the function and differentiation of osteoblasts and osteoclasts, depending on their exposure to mechanical loading (21). Considering the closely interconnected relation of these cells, it is easy to deduce that defects in osteoblast differentiation or function can cause disease by influencing the net effect on bone mass development $(22,23)$. Thus, models allowing the study of osteoblast biology can be insightful in delineating the disease mechanism.

\section{THE HUMBLE FIBROBLAST}

The fibroblast is generally known as a spindle-shaped adherent cell type and a common resident of mesenchymal stroma. It has been considered as a rather inert cell type for many years with the sole role of producing large amounts of ECM proteins, such as collagen type I, intended for the homeostasis of the connective tissue. However, it is steadily becoming more clear that fibroblasts have a much broader function, which includes the regulation of immune and inflammatory responses, for example during cutaneous wound repair (24), as well as during cell differentiation and behavior of neighboring cell types (25). It is also accepted that they represent a heterogeneous cell population, whose diversity extends not only across different anatomical locations but also within the same tissue, such as in the skin layers (26). Despite their abundance, their precise nature remains poorly characterized since they lack specific defining markers. It is perhaps partially because of this unspecialized character that they exhibit such a great plasticity and the ability to differentiate into other somatic cell types including osteogenic cells (27). Interestingly, it is a topic of great discussion whether fibroblasts are in fact the same cell type as mesenchymal stem cells (MSCs). According to the guidelines of the International Society for Cellular Therapy they are, as both cell types are plastic-adherent, share the presence and absence of the same MSC markers, and can differentiate into cells of the osteogenic, adipogenic, and chondrogenic lineages (27-29). MSCs were originally isolated from the bone marrow but have been subsequently identified in many tissues, including the skin. Their osteogenic properties have raised scientific attention with regards to their application in regenerative medicine (30-32). The similarities they share with the bone-forming MSC progenitors support the use of fibroblasts as an appropriate cell type to study osteogenesis.

\section{FIBROBLAST-BASED MODELS FOR THE STUDY OF BONE DISORDERS}

In the recent years, a plethora of reports have emerged, exploring the osteogenic properties of fibroblasts in producing osteoblasts suitable as disease models, as well as for potential bone regenerative applications. These refer mainly to two different ways of cell reprogramming for derivation of osteoblast cells: induced pluripotent stem cell (iPSC)-mediated differentiation and transdifferentiation. The first is based on the dedifferentiation of fibroblasts to an artificial stem cell type (iPSCs) by the induction of pluripotency. It is accomplished by the forced expression of the "Yamanaka factors" which typically include the Oct3/4, Sox2, c-Myc, and Klf4 transcription factors $(33,34)$. The iPSCs can be then directed toward the osteogenic cell lineage. The excitement revolving around the promising results of this approach is undoubtedly reflected in the numerous ongoing studies $(35,36)$. In addition to the multipotent plasticity of these cells, their patient specificity for autologous treatment and the lack of associated ethical issues, iPSCs have emerged in the last decade as a source of induced MSCs (iMSCs) (37), which are reported to have superior qualities to those of primary MSCs in cell survival and engraftment (38-40).

Despite these advantages, it is widely acknowledged that there are certain considerations with the use of iPSCs, such as the requirement for specialized technical resources for reprogramming and the consequences of manipulation for the induction of pluripotency, which include teratoma formation in regenerative applications. Minimization of these risks could be accomplished by optimizing the delivery of pluripotency factors by switching to non-integrative approaches, ensuring the absence of residual undifferentiated iPSCs, and monitoring the off-target effects (41). Another point of consideration is the potential disturbance of the cells differentiation potential as a result of reprogramming. Thus, iPSCs may not be suited to study a disorder in which the defect lies in cell differentiation. This is exemplified by the inhibition of iPSC generation and maintenance from fibroblasts of patients with fibrodysplasia ossificans progressiva (FOP), a severe disorder of heterotopic ossification. This was reported to be caused by the gene defect 
TABLE 1 | Overview of osteoblast cell derivation approaches.

\begin{tabular}{|c|c|c|c|}
\hline Fibroblast & Approach & Mouse model & Reference \\
\hline Gingival, dermal & $\begin{array}{l}\text { Retroviral delivery of RUNX-2,Osterix,Oct3/4 and L-Myc in } \\
\text { combination with ascorbic acid, } \beta \text {-glycerophosphate, } \\
\text { dexamethasone. }\end{array}$ & NOD/SCID & (6) \\
\hline Dermal & $\begin{array}{l}\text { Retroviral delivery of Oct9 with N-Myc in combination with } \\
\text { ascorbic acid, } \beta \text {-glycerophosphate, dexamethasone. }\end{array}$ & - & $(7)$ \\
\hline Gingival, dermal & $\begin{array}{l}\text { Plasmid delivery of Oct4, Osterix, and L-Myc in combination with } \\
\text { ascorbic acid, } \beta \text {-glycerophosphate, dexamethasone. }\end{array}$ & NOD/SCID & (8) \\
\hline Gingival, dermal foreskin & Adenovirus delivery of BMP7. & $\mathrm{NIH} \mathrm{III,} \mathrm{C57BL/6}$ & $(9-11)$ \\
\hline Gingival, dermal foreskin & Ascorbic acid, $\beta$-glycerophosphate, dexamethasone. & - & $(12)$ \\
\hline Dermal & Ascorbic acid, $\beta$-glycerophosphate, human platelet lysate. & - & $(13,14)$ \\
\hline Gingival & Ascorbic acid, $\beta$-glycerophosphate. & - & $(15)$ \\
\hline Interspinous ligament & Osteoclast cell-like conditioned media. & - & $(16)$ \\
\hline Dermal & $\begin{array}{l}\text { Ascorbic acid, } \beta \text {-glycerophosphate, dexamethasone, ALK5 } \\
\text { inhibitor II, vitamin D. }\end{array}$ & NOG & $(17)$ \\
\hline Dermal & Ascorbic acid, $\beta$-glycerophosphate, dexamethasone, TGF- $\beta$. & - & $(18)$ \\
\hline Dermal & $\begin{array}{l}\text { Ascorbic acid, } \beta \text {-glycerophosphate, vitamin D, p-tricalcium } \\
\text { phosphate scaffold. }\end{array}$ & - & $(19)$ \\
\hline Gingival & 5-aza-dC and BMP-2. & BNX & $(20)$ \\
\hline
\end{tabular}

of the disease in the activin receptor-like kinase 2 (ALK2) gene (42). These problems have been resolved in studies, in which iPSCs, and iMSCs from patient fibroblast-derived iPSCs, have been successfully used in FOP disease modeling $(43,44)$. Perhaps partly owing to these limitations, a low number of studies exist, concerning iPSCs from patients with rare bone disorders. In addition to FOP, these include iPSCs from Marfan syndrome fibroblasts (45), osteogenesis imperfecta bone marrow MSCs (38), craniometaphyseal dysplasia peripheral blood cells (46), thanatophoric dysplasia, and achondroplasia (47).

In an attempt to overcome these issues, research focus has shifted toward differentiation methods that can bypass the cumbersome step of iPSC generation (Figure 1). Transdifferentiation is the direct conversion of one differentiated cell type to another without the intermediate generation of iPSCs; however, whether and to which extent the pluripotency state is lacking, remains a point of discussion $(48,49)$. In addition to avoiding genomic instability and the risk of oncogenesis, an important advantage of transdifferentiation is primarily the lack of extensive cell manipulation, which means that the cells are possibly more likely to maintain their genetic makeup that may play a role in the accurate investigation of the disease mechanism. Below, several approaches of human osteoblast transdifferentiation in the field of bone disorders are summarized.

\section{TRANSGENE-MEDIATED OSTEOGENIC TRANSDIFFERENTIATION}

Yamamoto et al. showed that the retroviral transduction of human gingival fibroblasts with the two osteoblast-differentiation regulators RUNX-2 and Osterix, and the two reprogramming factors Oct3/4 and L-Myc, could induce their direct conversion to osteoblast-like cells (6). The differentiated cells showed a high expression of osteoblast-related genes, produced a high amount of calcified ECM, shared a similar global gene expression pattern with primary osteoblasts, and they were able to regenerate bone defect lesions that were surgically created in the femurs of NOD/SCID mice. They differed in the lower CpG methylation at the osteocalcin gene upstream region, compared to primary osteoblasts, but which was higher compared to their progenitor fibroblast cell line. Induction of the osteoblast generation could also be achieved by transient expression of the aforementioned factors. In a similar study, the retroviral-mediated expression of combined Oct9 with $\mathrm{N}-\mathrm{Myc}$ was identified as the most potent for the osteogenic conversion, which was also based on the expression of osteogenic genes RUNX-2 and osteocalcin, as well as on the production of calcified bone matrix (7). In order to avoid the unwanted effects of retroviral integration in the genome, the same group attempted the expression of Oct4, Osterix, and L-Myc with a plasmid vector in human fibroblasts (8). This led to the induction of an osteoblast-like phenotype based on the expression of osteoblast-specific genes, in vitro deposition of minerals, alkaline phosphatase activity, and calcified body formation following implantation in the testis of NOD/SCID mice. Regarding the latter, no teratoma formation was observed in sharp contrast to implanted iPSCs. A pertinent question is the requirement of pluripotency factors in combination with the expression of master switch genes or the common osteogenic media. Even though pluripotency was not detected in the transitioning cells, it can be assumed that they provide some level of stemness, which can prime them for osteogenic conversion by the cues provided from the other factors (6).

Considering that the TGF- $\beta$ superfamily regulates diverse aspects of the skeletal system (50), the osteo-inductive properties of bone morphogenetic proteins (BMPs) have been explored. 


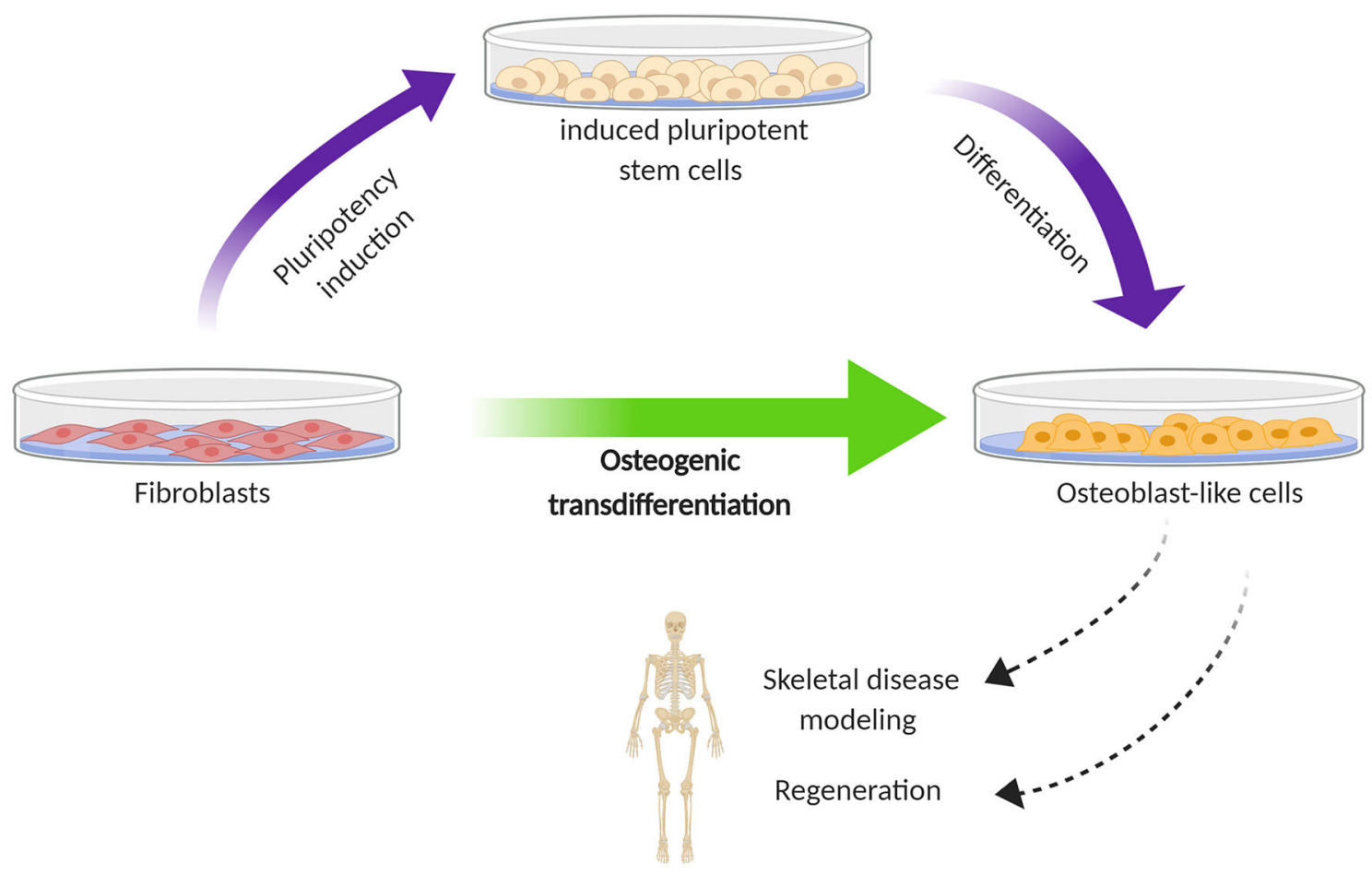

FIGURE 1 | Schematic diagram illustrating the difference in cell reprogramming between iPSC-mediated differentiation (two step) and transdifferentiation (one step) for the generation of osteoblast-like cells from human fibroblasts. The first is based on directing fibroblasts toward induced pluripotent stem cells, which are subsequently subjected to osteogenic differentiation. In the second, this pluripotency stage is bypassed; fibroblasts are directly converted to osteoblast-like cells. The generation of osteoblast-like cells from fibroblasts holds promise for modeling the process of skeletal disorders and exploring regenerative therapies.

Krebsbach et al. reported that ex vivo adenovirus BMP7 -transduced fibroblasts have bone-forming properties when transplanted into immunocompromised mice (9). The same group subsequently showed that adenovirus BMP-7-transduced fibroblasts via subcutaneous injection can form ossicles in mice and they can also repair segmental defects in rat femurs. The in vivo osteoblast conversion of the transduced fibroblasts in the diffusion chambers took place without contact with the host cells, stressing the osteogenic role of BMP-7 (10). This is in agreement with the suppression of the osteoblast phenotype after addition of the BMP inhibitor noggin in osteogenic media of human fibroblasts seeded in p-tricalcium phosphate scaffolds (19). Chen et al. also showed that the knockdown of the BMP signalingregulator SMAD4 attenuates the osteogenic differentiation of fibroblasts after adenovirus-mediated BMP-7 expression (11). These studies have not compared BMP-7 with other BMPs, which have also shown to have osteogenic capacity in mouse fibroblasts (51); whether this applies to human fibroblasts remains to be shown.

\section{TRANSGENE FREE-MEDIATED OSTEOGENIC TRANSDIFFERENTIATION}

In the described studies, as well as in other studies with untransfected fibroblasts (12), cells were treated with osteogenic media, which included supplementation with ascorbic acid, $\beta$-glycerophosphate, and dexamethasone. Dexamethasone is a synthetic glucocorticoid which is frequently used in recipes of osteogenic media to promote the in vitro commitment of cells toward the osteogenic cell lineage (52). However, glucocorticoidinduced osteoporosis clearly points to a differential effect on osteogenesis; the boundary distinguishing its ability to promote or suppress bone formation is still undefined $(53,54)$. In order to provide an alternative for dexamethasone and fetal calf serum, we have turned to growth factors. We have developed an in vitro method of osteogenic transdifferentiation based on human platelet lysate $(13,14)$. Platelet lysate provides numerous growth factors (55), which have been shown to promote osteogenic differentiation of bone marrow-derived MSCs (56, 57) and prevent osteoporosis development in ovariectomized mice (57). In this model, we have observed that dermal fibroblasts from FOP patients show an enhanced potential for osteogenic transdifferentiation in agreement with the heterotopic ossification characterizing this disease (13) A similar model for osteogenesis in FOP also exists with periodontal ligament fibroblasts (15). We also used our model to investigate the effect of the identified genetic variants in AIFM1 on protein level in patients with spondylometaphyseal dysplasia (14). AIFM1 encodes the mitochondrial apoptosisinducing factor 1 , which was undetectable in dermal fibroblasts; the osteogenic transdifferentiation of fibroblasts to osteoblastlike cells allowed the confirmation of the pathogenic effect 
of the AIFM1 variant in the differentiated cell type modeling the disease. Differentiation of fibroblasts toward the osteoblast lineage was also demonstrated with treatment of osteoclastconditioned media (16). It is known that osteoclasts secrete factors affecting osteoblast differentiation (58); the osteoclast factors mediating the osteoblast conversion were not addressed in this study. The identification of key osteogenic factors in the platelet lysate and osteoclast-conditioned media can aid the optimization of transgene-free protocols.

The chemical inhibition of the ALK5 receptor, a TGF- $\beta$ type I receptor mediating signaling by TGF- $\beta$ ligands, with the use of the ALK5 inhibitor II, directed the conversion of human dermal fibroblasts to osteoblast-like cells (17). In particular, the combination of ALK5 inhibitor II and vitamin D3 yielded the highest enhancement in osteoblast differentiation. The implantation of the differentiated cells in created bone lesions of immunodeficient NOG mice resulted in bone healing, as evaluated by histological analysis of callus formation and ossification. Interestingly, the stimulation of osteoblastogenesis by ALK5 inhibition is the opposite of what we observed in our study with the different ALK5 inhibitor GW788388 (13). In another study, the addition of TGF- $\beta$ to osteogenic media was shown to improve the capacity of dermal fibroblasts for osteogenic transdifferentiation, although it did not contribute to mineralization (18). These differences may be attributed to the different growth factor compositions between these models, as well as to the different properties of the chemical inhibitors; for example, GW788388 is known to additionally target ALK4 and ALK7, which are TGF- $\beta$ type I receptors for activin signaling (59). In a different approach, Cho et al. used BMP2 treatment combined with compoundinduced demethylation of the hypermethylated $\mathrm{CpG}$ islands of the RUNX2 and ALP genes to drive the direct differentiation of human gingival fibroblasts to functional osteoblasts, as shown by the subcutaneous ectopic bone formation in BNX mice after implantation of the epigenetically modified cells (20). These studies highlight the potential of chemical approaches in osteogenic transdifferentiation as a more controlled, simple, and low-cost alternative to growth factors.

\section{CHONDROGENIC TRANSDIFFERENTIATION}

Bone development takes place through two different modes: intramembranous or endochondral ossification. The first is characterized by the differentiation of progenitor mesenchymal cells to osteoblasts, whereas the second is mediated by an

\section{REFERENCES}

1. Mäkitie RE, Costantini A, Kämpe A, Alm JJ, Mäkitie O. New insights into monogenic causes of osteoporosis. Front Endocrinol. (2019) 10:70. doi: 10.3389 /fendo. 2019.00070

2. McCarthy EF, Genetic diseases of bones and joints. Semin Diagn Pathol. (2011) 28:26-36. doi: 10.1053/j.semdp.2011.01.004 intermediate cartilage phase preceding bone tissue development (60). Thus, given that endochondral ossification is an integral part of skeletogenesis, the availability of models to study the chondrocytes certainly has the possibility to deliver significant insights into the dysregulation of this process in certain disorders (61). Similar to osteogenic transdifferentiation, several protocols exist for chondrogenic transdifferentiation of fibroblasts, which are based on growth factor stimulation, forced expression of key transcription factors, scaffold biomaterials, and hypoxic conditions (62).

\section{CONCLUSIONS}

Osteogenic transdifferentiation is an attractive route to generate cells of the osteogenic cell lineage. Available examples show that they can be promising in modeling of bone diseases. Several studies exist presenting different experimental options for fibroblast commitment toward the osteogenic cells; many of these do not make use of transgene introduction, which offers an advantage over iPSCs. The latter are derived after fibroblast reprogramming and subsequent differentiation, a process that requires extensive genetic modification, is technically demanding, and may pose malignancy risks in tissue regeneration. On the other hand, the fact that limited studies exist about osteogenic transdifferentiation means that we still have an incomplete understanding of the mechanism and the whole spectrum of potential advantages and shortcomings. With this review, we hope to generate excitement and ideas about the under-investigated osteogenic transdifferentiation as an alternative for the iPSC detour. Harnessing the osteogenic potential of the easily attainable fibroblasts is an attractive prospect for the study of bone pathophysiology and the future development of new technologies for bone regeneration therapy.

\section{AUTHOR CONTRIBUTIONS}

DM has carried out the conception and writing of the article. All authors contributed to the article and approved the submitted version.

\section{FUNDING}

This work was kindly funded by the Horstingstuit foundation.

\section{ACKNOWLEDGMENTS}

Figure 1 was created with BioRender.com. 
6. Yamamoto K, Kishida T, Sato Y, Nishioka K, Ejima A, Fujiwara H, et al. Direct conversion of human fibroblasts into functional osteoblasts by defined factors. Proc Natl Acad Sci USA. (2015) 112:6152-7. doi: 10.1073/pnas.1420713112

7. Mizoshiri N, Kishida T, Yamamoto K, Shirai T, Terauchi R, Tsuchida S, et al. Transduction of Oct 6 or Oct 9 gene concomitant with myc family gene induced osteoblast-like phenotypic conversion in normal human fibroblasts. Biochem Biophys Res Commun. (2015) 467:1110-6. doi: 10.1016/j.bbrc.2015.10.098

8. Yamamoto K, Sato Y, Honjo K, Ichioka H, Oseko F, Sowa Y, et al. Generation of directly converted human osteoblasts that are free of exogenous gene and xenogenic protein. J Cell Biochem. (2016) 117:2538-45. doi: 10.1002/jcb.25546

9. Krebsbach PH, Gu K, Franceschi RT, Rutherford RB. Gene therapy-directed osteogenesis: BMP-7-transduced human fibroblasts form bone in vivo. Hum Gene Ther. (2000) 11:1201-10. doi: 10.1089/10430340050015248

10. Rutherford RB, Moalli M, Franceschi RT, Wang D, Gu K, Krebsbach $\mathrm{PH}$. Bone morphogenetic protein-transduced human fibroblasts convert to osteoblasts and form bone in vivo. Tissue Eng. (2002) 8:441-52. doi: 10.1089/107632702760184709

11. Chen F, Bi D, Cheng C, Ma S, Liu Y, Cheng K. Bone morphogenetic protein 7 enhances the osteogenic differentiation of human dermal-derived CD105+ fibroblast cells through the Smad and MAPK pathways. Int J Mol Med. (2019) 43:37-46. doi: 10.3892/ijmm.2018.3938

12. Monterubbianesi R, Bencun M, Pagella P, Woloszyk A, Orsini G, Mitsiadis TA. A comparative in vitro study of the osteogenic and adipogenic potential of human dental pulp stem cells, gingival fibroblasts and foreskin fibroblasts. Sci Rep. (2019) 9:1761. doi: 10.1038/s41598-018-37981-x

13. Micha D, Voermans E, Eekhoff MEW, van Essen HW, ZandiehDoulabi B, Netelenbos C, et al. Inhibition of TGF $\beta$ signaling decreases osteogenic differentiation of fibrodysplasia ossificans progressiva fibroblasts in a novel in vitro model of the disease. Bone., (2016) 84:169-80. doi: 10.1016/j.bone.2016.01.004

14. Miyake N, Wolf NI, Cayami FK, Crawford J, Bley A, Bulas D, et al. $\mathrm{X}$-linked hypomyelination with spondylometaphyseal dysplasia (H-SMD) associated with mutations in AIFM1. Neurogenetics. (2017) 18:185-94. doi: 10.1007/s10048-017-0520-x

15. de Vries TJ, Schoenmaker T, Micha D, Hogervorst J, Bouskla S, Forouzanfar $\mathrm{T}$, et al. Periodontal ligament fibroblasts as a cell model to study osteogenesis and osteoclastogenesis in fibrodysplasia ossificans progressiva. Bone. (2018) 109:168-177. doi: 10.1016/j.bone.2017.07.007

16. Yu F, Cui Y, Zhou X, Zhang X, Han J. Osteogenic differentiation of human ligament fibroblasts induced by conditioned medium of osteoclast-like cells. Biosci Trends. (2011) 5:46-51. doi: 10.5582/bst.2011.v5.2.46

17. Yamamoto K, Kishida T, Nakai K, Sato Y, Kotani SI, Nishizawa Y, et al. Direct phenotypic conversion of human fibroblasts into functional osteoblasts triggered by a blockade of the transforming growth factor- $\beta$ signal. Sci Rep. (2018) 8:8463. doi: 10.1038/s41598-018-26745-2

18. Aloise AC, Pereira MD, Duailibi SE, Gragnani A, Ferreira LM. TGF- $\beta 1$ on induced osteogenic differentiation of human dermal fibroblast. Acta Cir Bras. (2014) 29:1-6. doi: 10.1590/S0102-86502014001300001

19. Hee CK, Nicoll SB. Induction of osteoblast differentiation markers in human dermal fibroblasts: potential application to bone tissue engineering. Conf Proc IEEE Eng Med Biol Soc. (2006) 2006:521-4. doi: 10.1109/IEMBS.2006.259308

20. Cho Y, Kim B, Bae H, Kim W, Baek J, Woo K, et al. Direct gingival fibroblast/osteoblast transdifferentiation via epigenetics. J Dent Res. (2017) 96:555-61. doi: 10.1177/0022034516686745

21. Bonewald LF. The amazing osteocyte. J Bone Miner Res. (2011) 26:229-38. doi: 10.1002/jbmr.320

22. Marie PJ, Kassem M. Osteoblasts in osteoporosis: past, emerging, and future anabolic targets. Eur J Endocrinol. (2011)165:1-10. doi: 10.1530/EJE-11-0132

23. Johnson ML. How rare bone diseases have informed our knowledge of complex diseases. Bonekey Rep. (2016) 5:839. doi: 10.1038/bonekey.2016.69

24. Tracy LE, Minasian RA, Caterson EJ. Extracellular matrix and dermal fibroblast function in the healing wound. Adv Wound Care. (2016) 5:119-36. doi: 10.1089/wound.2014.0561

25. Sorrell JM, Caplan AI. Fibroblasts-a diverse population at the center of it all. Int Rev Cell Mol Biol. (2009)276:161-214. doi: 10.1016/S1937-6448(09)76004-6
26. Sorrell JM, Caplan AI. Fibroblast heterogeneity: more than skin deep. J Cell Sci. (2004) 117:667-75. doi: 10.1242/jcs.01005

27. Denu RA, Nemcek S, Bloom DD, Goodrich AD, Kim J, Mosher DF, et al. Fibroblasts and mesenchymal stromal/stem cells are phenotypically indistinguishable. Acta Haematol. (2016) 136:85-97. doi: 10.1159/000445096

28. Haniffa MA, Collin MP, Buckley CD, Dazzi F. Mesenchymal stem cells: the fibroblasts' new clothes? Haematologica. (2009) 94:258-63. doi: 10.3324/haematol.13699

29. Soundararajan M, Kannan S. Fibroblasts and mesenchymal stem cells: two sides of the same coin? J Cell Physiol. (2018) 233:9099-109. doi: $10.1002 /$ jcp. 26860

30. Infante A, Rodríguez CI. Osteogenesis and aging: lessons from mesenchymal stem cells. Stem Cell Res Ther. (2018) 9:244. doi: 10.1186/s13287-018-0995-x

31. Wei X, Yang X, Han ZP, Qu FF, Shao L, Shi YF. Mesenchymal stem cells: a new trend for cell therapy. Acta Pharmacol Sinica. (2013) 34:747-54. doi: 10.1038 /aps. 2013.50

32. Ichim TE, O'Heeron $\mathrm{P}$, Kesari S. Fibroblasts as a practical alternative to mesenchymal stem cells. J Transl Med. (2018) 16:212. doi: 10.1186/s12967-018-1536-1

33. Takahashi K, Tanabe K, Ohnuki M, Narita M, Ichisaka T, Tomoda K, et al. Induction of pluripotent stem cells from adult human fibroblasts by defined factors. Cell. (2007) 131:861-72. doi: 10.1016/j.cell.2007.11.019

34. Yu J, Vodyanik MA, Smuga-Otto K, Antosiewicz-Bourget J, Frane JL, Tian S, et al. Induced pluripotent stem cell lines derived from human somatic cells. Science. (2007) 318:1917-20. doi: 10.1126/science.1151526

35. Bastami F, Nazeman P, Moslemi H, Rezai Rad M, Sharifi K, Khojasteh A. Induced pluripotent stem cells as a new getaway for bone tissue engineering: a systematic review. Cell Prolif. (2017) 50:e12321. doi: 10.1111/cpr.12321

36. Csobonyeiova M, Polak S, Zamborsky R, Danisovic L. iPS cell technologies and their prospect for bone regeneration and disease modeling: a mini review. J Adv Res. (2017) 8:321-7. doi: 10.1016/j.jare.2017.02.004

37. Sabapathy V, Kumar S. hiPSC-derived iMSCs: nextGen MSCs as an advanced therapeutically active cell resource for regenerative medicine. J Cell $\mathrm{Mol} \mathrm{Med}$. (2016) 20:1571-88. doi: 10.1111/jcmm.12839

38. Deyle DR, Khan IF, Ren G, Wang PR, Kho J, Schwarze U, et al. Normal collagen and bone production by gene-targeted human osteogenesis imperfecta iPSCs. Mol Ther. (2012) 20:204-13. doi: 10.1038/mt.2011.209

39. Villa-Diaz LG, Brown SE, Liu Y, Ross AM, Lahann J, Parent JM, Krebsbach $\mathrm{PH}$. Derivation of mesenchymal stem cells from human induced pluripotent stem cells cultured on synthetic substrates. Stem Cells. (2012) 30:1174-81. doi: 10.1002/stem.1084

40. Pellegrini G, Traverso CE, Franzi AT, Zingirian M, Kinoshita S. Exosomes released from human induced pluripotent stem cells-derived MSCs facilitate cutaneous wound healing by promoting collagen synthesis and angiogenesis. J Transl Med. (2013) 13:49.

41. Doss MX, Sachinidis A. Current challenges of iPSC-based disease modeling and therapeutic implications. Cells. (2019) 8:403. doi: 10.3390/cells8050403

42. Hamasaki M, Hashizume Y, Yamada Y, Katayama T, Hohjoh H, Fusaki $\mathrm{N}$, et al. Pathogenic mutation of ALK2 inhibits induced pluripotent stem cell reprogramming and maintenance: mechanisms of reprogramming and strategy for drug identification. Stem Cells. (2012) 30:2437-49. doi: $10.1002 /$ stem. 1221

43. Cai J, Orlova VV, Cai X, Eekhoff EMW, Zhang K, Pei D, et al. Induced pluripotent stem cells to model human fibrodysplasia ossificans progressiva. Stem Cell Rep. (2015) 5:963-70. doi: 10.1016/j.stemcr.2015.10.020

44. Matsumoto Y, Ikeya M, Hino K, Horigome K, Fukuta M, Watanabe M, et al. New protocol to optimize ips cells for genome analysis of fibrodysplasia ossificans progressiva. Stem Cells. (2015) 33:1730-42. doi: 10.1002/stem.1981

45. Quarto N, Leonard B, Li S, Marchand M, Anderson E, Behr B, et al. Skeletogenic phenotype of human marfan embryonic stem cells faithfully phenocopied by patient-specific induced-pluripotent stem cells. Proc Natl Acad Sci USA. (2012). 109:215-20. doi: 10.1073/pnas.1113442109

46. Chen IP, Fukuda K, Fusaki N, Iida A, Hasegawa M, Lichtler A, et al Induced pluripotent stem cell reprogramming by integration-free sendai virus vectors from peripheral blood of patients with craniometaphyseal dysplasia. Cell Reprogram. (2013) 15:503-13. doi: 10.1089/cell.20 13.0037 
47. Yamashita A, Morioka M, Kishi H, Kimura T, Yahara Y, Okada M, et al. Statin treatment rescues FGFR3 skeletal dysplasia phenotypes. Nature. (2014) 513:507-11. doi: 10.1038/nature13775

48. Cieślar-Pobuda A, Knoflach V, Ringh MV, Stark J, Likus W, Siemianowicz $\mathrm{K}$, et al. Transdifferentiation and reprogramming: overview of the processes, their similarities and differences. Biochim Biophys Acta Mol Cell Res. (2017) 1864:1359-69 doi: 10.1016/j.bbamcr.2017.04.017

49. Reid A, and Tursun B. Transdifferentiation: do transition states lie on the path of development? Curr Opin Syst Biol. (2018) 11:18-23. doi: 10.1016/j.coisb.2018.07.004

50. Poniatowski LA, Wojdasiewicz P, Gasik R, Szukiewicz D. Transforming growth factor beta family: Insight into the role of growth factors in regulation of fracture healing biology and potential clinical applications. Mediat Inflam. (2015). 2015:137823. doi: 10.1155/2015/137823

51. Myllylä RM, Haapasaari KM, Lehenkari P, Tuukkanen J. Bone morphogenetic proteins 4 and 2/7 induce osteogenic differentiation of mouse skin derived fibroblast and dermal papilla cells. Cell Tissue Res. (2014) 355:463-70. doi: 10.1007/s00441-013-1745-0

52. Langenbach F, Handschel J. Effects of dexamethasone, ascorbic acid and $\beta$ glycerophosphate on the osteogenic differentiation of stem cells in vitro. Stem Cell Res Ther. (2013) 4:117. doi: 10.1186/scrt328

53. Rimando MG, Wu H, Lee C, Kuo S, Lo Y, Liu Y, et al. Bimodal effects of dexamethasone on osteogenic differentiation of mesenchymal stromal cells. Cytotherapy. (2016) 18:S77-8. doi: 10.1016/j.jcyt.2016.03.158

54. Zhou H, Cooper MS, Seibel MJ. Endogenous glucocorticoids and bone. Bone Res. (2013) 1:107-19. doi: 10.4248/BR201302001

55. Fekete N, Gadelorge M, Fürst D, Maurer C, Dausend J, Fleury-Cappellesso $\mathrm{S}$, et al. Platelet lysate from whole blood-derived pooled platelet concentrates and apheresis-derived platelet concentrates for the isolation and expansion of human bone marrow mesenchymal stromal cells: production process, content and identification of active comp. Cytotherapy. (2012) 14:540-54. doi: 10.3109/14653249.2012.655420

56. Jonsdottir-Buch SM, Lieder R, Sigurjonsson OE. Platelet lysates produced from expired platelet concentrates support growth and osteogenic differentiation of mesenchymal stem cells. PLoS ONE. (2013) 8:e68984. doi: 10.1371/journal.pone.0068984

57. W-Lo C, J-Chiou F, Gelovani JG, M-Cheong L, C-Lee M, H-Liu Y, et al. Transplantation of embryonic fibroblasts treated with platelet-rich plasma induces osteogenesis in SAMP8 mice monitored by molecular imaging. J Nucl Med. (2009) 50:765-73. doi: 10.2967/jnumed.108.0 57372

58. Sims NA, Martin TJ. Coupling signals between the osteoclast and osteoblast: how are messages transmitted between these temporary visitors to the bone surface? Front Endocrinol. (2015) 6:41. doi: 10.3389/fendo.2015.00041

59. Petersen M, Thorikay M, Deckers M, Van Dinther M, Grygielko ET, Gellibert F, et al. Oral administration of GW788388, an inhibitor of TGF- $\beta$ type I and II receptor kinases, decreases renal fibrosis. Kidney Int. (2008) 73:705-15. doi: 10.1038/sj.ki.5002717

60. Berendsen AD, Olsen BR. Bone development. Bone. (2015) 80:14-8. doi: 10.1016/j.bone.2015.04.035

61. Shore EM. Fibrodysplasia ossificans progressiva (FOP): a disorder of extraskeletal endochondral ossification. Semin Arthritis Rheum. (2013) 42:546. doi: 10.1016/j.semarthrit.2012.12.010

62. Driessen BJH, Logie C, Vonk LA. Cellular reprogramming for clinical cartilage repair. Cell Biol Toxicol. (2017) 33:329-49. doi: $10.1007 /$ s10565-017-9382-0

Conflict of Interest: The authors declare that the research was conducted in the absence of any commercial or financial relationships that could be construed as a potential conflict of interest.

Copyright (c) 2020 Claeys, Bravenboer, Eekhoff and Micha. This is an open-access article distributed under the terms of the Creative Commons Attribution License (CC $B Y)$. The use, distribution or reproduction in other forums is permitted, provided the original author(s) and the copyright owner(s) are credited and that the original publication in this journal is cited, in accordance with accepted academic practice. No use, distribution or reproduction is permitted which does not comply with these terms. 